\title{
Anaesthesia and Intensive Care A to Z: An Encyclopaedia of Principles and Practice
}

\author{
Steven M. Yentis, Nicholas P. Hirsch, Gary B. Smith. Churchill Livingstone, \\ Elsevier, 2009, 4th edition, 569 pp, ISBN 9780443067853
}

Richard Bowry, MB

Published online: 30 September 2009

(C) Canadian Anesthesiologists' Society 2009

Since the first edition's publication 15 years ago, this textbook has remained popular for postgraduate anesthesia trainees studying for the Royal College of Anaesthetist's Fellowship Examinations in the UK. It has been updated once again and is now in its fourth edition.

The textbook's innovative encyclopedia-style layout includes alphabetically arranged concise entries, clear welllabeled diagrams, relevant equations, and quick-reference tables. Extensive and easily identified cross-references throughout the text allow the reader to shift easily between related topics. The entries are supported with up-to-date references where appropriate.

The text's content covers the requisite topics for many postgraduate anesthesia examinations. In addition to clinical information on anesthesia and medical and surgical intensive care, basic sciences items are included, such as pharmacology, anatomy, physiology, physics, equipment, and medical statistics. The end product is a single volume that equally describes the landmarks for a celiac plexus block, the pKa of lidocaine, an explanation of the Sequential Organ Failure Assessment (SOFA) score, and the anesthetic considerations for patients with pulmonary hypertension.

The readership is likely to be as diverse as the content. Clearly, this book can help postgraduate trainees prepare for professional examinations. The easy-to-use format, together with the quick and easy explanations, give this book a wider appeal. It could easily be at home on the shelf of an experienced teacher looking for inspiration, a clinician investigating the management of some rare condition, or a novice anesthesia assistant learning the basic principles of anesthesia.

It is evident, from browsing though the book's contents, that the UK authors endeavored to incorporate relevant material for readers in the USA and Canada, and for the most part, they achieved their objective. Drugs were identified with their Recommended International Non-proprietary Names (rINNs), and drugs only available in the USA and Canada were also included. However, the textbook included a few discrepancies that could cause some confusion. There are differing definitions or standards applied to neuroleptic anesthesia and pressures in piped gases. Also, there were notable omissions, including anesthesia delivery unit and conscious sedation. It would be helpful if these were addressed in the next edition.

In summary, this is a well written, current, and concise encyclopedia-style textbook that can be useful to teacher and student alike. Although it may not replace the more hefty volumes currently used for fellowship examination preparation, the short entries are ideal for taking advantage of the occasional 15-min breaks during the day.

R. Bowry, MB ( $\square)$

University of Toronto, Toronto, Canada

e-mail: bowryr@smh.toronto.on.ca 